\title{
Attitudes towards conservation of the Endangered red panda Ailurus fulgens in Nepal: a case study in protected and non-protected areas
}

\author{
Hari P. Sharma, Jerrold L. Belant and Pei-Jen L. Shaner
}

\begin{abstract}
The red panda Ailurus fulgens is categorized as Endangered on the IUCN Red List and is threatened by anthropogenic pressures such as livestock grazing. We surveyed people living in or near protected areas and people living away from protected areas in Nepal, to understand human attitudes towards red panda conservation. Given Nepal's participatory approach to managing protected areas, we hypothesized that local people living in or near protected areas would have more positive attitudes towards red panda conservation than those in non-protected areas. Ninety percent of the 142 respondents had positive attitudes, with people living in or near protected areas expressing less positive attitudes than those in non-protected areas. Despite this difference between protected and non-protected areas, people were generally positive towards red panda conservation. However, positive attitudes did not necessarily translate to sustainable resource-use behaviour. We found there was a high prevalence of both livestock grazing and livestock disease in red panda habitat. We suggest that alternative farming practices (e.g. stall-feeding of livestock) and awareness programmes (e.g. education on the conservation status and legal protection of red pandas, and livestock-wildlife disease transmission) could be important tools to improve conservation attitudes and protect red pandas in Nepal.
\end{abstract}

Keywords Ailurus fulgens, conservation attitudes, Nepal, people-park relationships, protected areas, red pandas, threatened species, wildlife conservation

Supplementary material for this article can be found at https://doi.org/10.1017/So030605317000990

\section{Introduction}

$\mathrm{P}$ eople's attitudes towards conservation can be influenced by their socio-economic backgrounds (e.g.

Hari P. Sharma ${ }^{*}$ and Pei-Jen L. Shaner (Corresponding author) Department of Life Science, National Taiwan Normal University, Taipei, Taiwan

E-mail pshaner@ntnu.edu.tw

Jerrold L. Belant Carnivore Ecology Laboratory, Forest and Wildlife Research Center, Mississippi State University, Mississippi, USA

*Also at: Biodiversity Program, Taiwan International Graduate Program, Academia Sinica, Taipei, Taiwan, and Central Department of Zoology, Tribhuvan University, Kirtipur, Kathmandu, Nepal

Received 31 January 2017. Revision requested 28 April 2017.

Accepted 7 June 2017. First published online 27 September 2017.
Bhattarai \& Fischer, 2014; Mir et al., 2015), the perceived costs and benefits of conservation (e.g. Dewu \& Røskaft, 2017), cultural and aesthetic values (e.g. Glatston \& Gebauer, 2011; Gebresenbet et al., 2017), personal experiences and knowledge (e.g. Bhattarai \& Fischer, 2014; Talukdar \& Gupta, 2017), and management intervention such as economic incentives (e.g. Mishra et al., 2003; Baral \& Heinen, 2007). Protected areas often have stronger management interventions than other areas, both in terms of restrictions on natural resource use and economic incentives (Baral \& Heinen, 2007), and therefore people living in or near protected areas and extracting natural resources from protected areas may have different conservation attitudes than those living away from protected areas, and by comparing these attitudes we can tailor the design and implementation of conservation projects accordingly.

The red panda Ailurus fulgens is categorized as Endangered on the IUCN Red List (Glatston et al., 2015). The species is distributed throughout the Himalaya region (Kandel et al., 2015), where it is vulnerable to anthropogenic threats such as livestock grazing (Sharma \& Belant, 2010; Dorji et al., 2012; Sharma et al., 2014). Red pandas do not cause harm to people or their property (e.g. livestock predation, crop losses, human injuries; Acharya et al., 2016), and cultural beliefs in some regions of Nepal can positively influence people's attitudes towards red pandas. In a 2008 survey in Rara National Park, HPS recorded this statement from Lal Bahadur Rokaya (former President of the Buffer Zone Management Committee, Rara National Park): 'Only lucky people are able to see red pandas. If you see them alive you will receive good news very soon'. Furthermore, the ramma or shamans (Jhakri) of Mugar and Dalit communities in western Nepal previously used the skin or hair of red pandas in their dress during rituals to avoid being attacked by spirits (Glatston \& Gebauer, 2011). Although, given their rarity, red pandas are no longer used in rituals (Dil Man Gharti Magar, Rukum district, pers. comm.), these examples suggest the red panda is perceived positively in local cultures.

The aim of this study was to provide empirical data on people's attitudes towards red panda conservation in Nepal, to inform the development of effective and practical conservation action plans. We hypothesized that (1) local people generally have positive attitudes towards red panda conservation, given their cultural beliefs and that red pandas do not come into conflict with people, and (2) people living in or near protected areas have more positive attitudes 


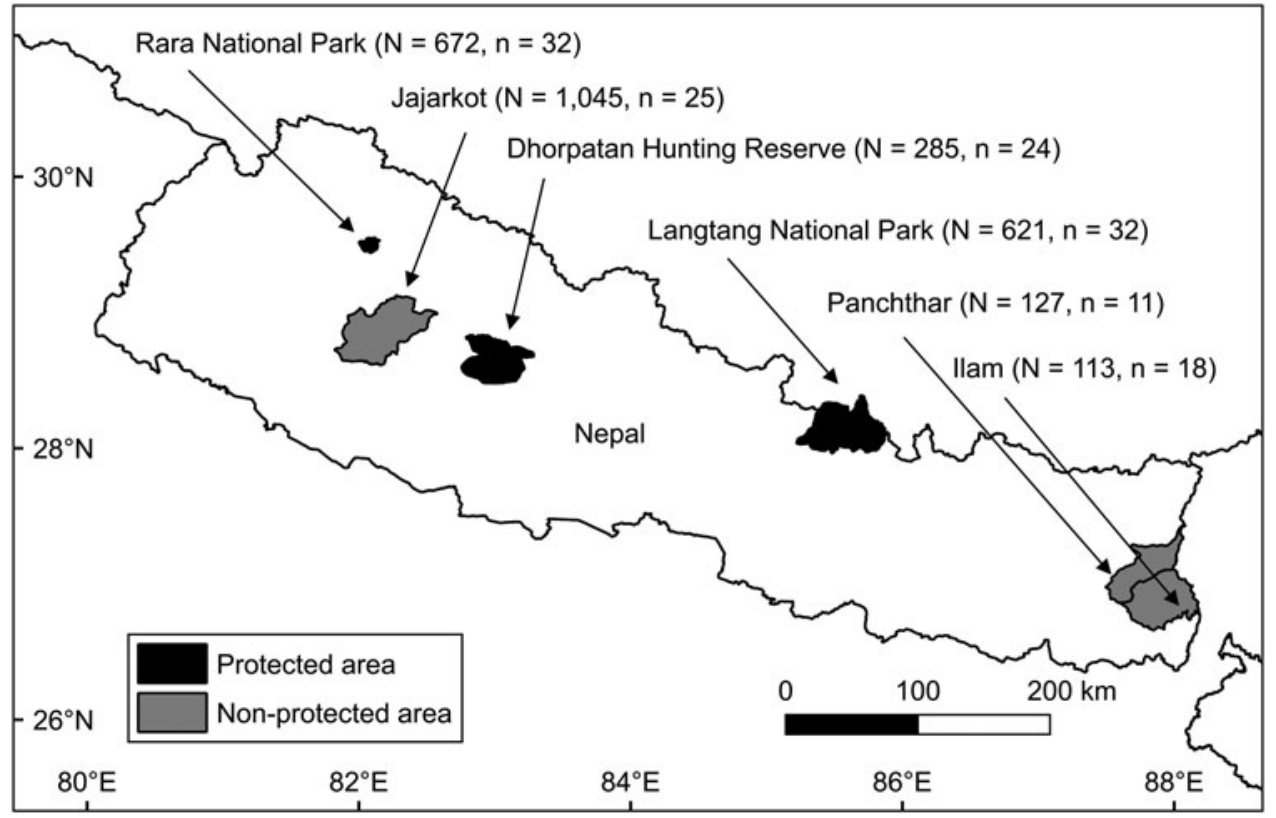

FIG. 1 Locations of the six study sites (Supplementary Table S1) in Nepal where semi-structured questionnaire surveys were conducted in 2015 to investigate people's attitudes towards conservation of the red panda Ailurus fulgens. $\mathrm{N}$, number of households at each site (CBS, 2011; for Ilam, Williams, 2004); n, number of households interviewed. towards conservation than those in non-protected areas, given the participatory approaches to protected-area management adopted by the Government of Nepal (e.g. sharing tourism revenue with local people living in or near protected areas; Budhathoki, 2004).

In addition, we explored the associations between conservation attitudes and individual-level factors (i.e. demographic and socio-economic factors, factors related to individual experiences, and knowledge). To provide information for conservation planning we surveyed people's opinions on the benefits of red panda presence, the tools used to protect red pandas, and the primary sources of information through which people gain knowledge about red pandas.

\section{Study area}

We chose six study sites (Fig. 1): three protected areas (Rara National Park, Dhorpatan Hunting Reserve and Langtang National Park), and three non-protected areas (Ilam, Panchthar and Jajarkot). All six sites are rural and remote, and we selected these sites because red pandas are known to have occurred in these areas (HPS, pers. obs.), and they are geographically representative of the spatial extent of suitable habitat for the red panda in Nepal (Kandel et al., 2015). The two National Parks are Category II protected areas, and Dhorpatan Hunting Reserve is a Category VI protected area (IUCN, 2017). People are allowed to continue living in Langtang National Park and Dhorpatan Hunting Reserve if they had been living there prior to establishment but no new settlements are allowed. People are not permitted to live inside Rara National Park. According to
Himalayan Park Regulations (HMG, 1979), people can extract natural resources from protected areas for personal use but not for commercial purposes. The three nonprotected areas are $60-70 \mathrm{~km}$ distant from any protected areas, and people there extract natural resources from locally managed community forests.

\section{Methods}

In 2015 we interviewed 142 people, 88 from protected areas (Rara National Park: 32, Dhorpatan Hunting Reserve: 24, Langtang National Park: 32) and 54 from non-protected areas (Ilam: 18, Panchthar: 11, Jajarkot: 25; Fig. 1), using a semi-structured questionnaire (Supplementary Table S1). All interviewees at Langtang National Park lived inside the Park, all interviewees at Rara National Park lived near the Park, and the interviewees at Dhorpatan Hunting Reserve were seasonal residents, living inside the Reserve during March-October.

We interviewed one adult ( $\geq 21$ years old) from each household. Interviewees were encountered opportunistically while they were engaging in activities such as livestock grazing or natural resource collection in red panda habitat. We showed them photographs of red pandas to ensure that they recognized the species. Although young people's attitudes are important to long-term conservation, we found that young people had no knowledge of red pandas (e.g. we spoke with an 8- and a 10-year old child and neither of them could identify red pandas in the photographs). We collected demographic and socio-economic data, including gender, age, education, occupation, family size, income, whether the interviewee owned livestock, the number of 
TABLE 1 Demographic and socio-economic backgrounds of interview respondents from three protected areas $(n=88)$ and three nonprotected areas $(n=54)$ in Nepal (Fig. 1$)$.

\begin{tabular}{|c|c|c|c|}
\hline Variable & Protected areas & Non-protected areas & Statistics ${ }^{1}$ \\
\hline Gender & $63 \%$ males & $56 \%$ males & Fisher's exact test, two-tailed, $\mathrm{P}=0.48$ \\
\hline Age & Median $=35$ & Median $=37$ & Kruskal-Wallis test, $\chi^{2}=0.05, \mathrm{P}=0.82$ \\
\hline Occupation & $67 \%$ agriculture only & $72 \%$ agriculture only & Fisher's exact test, two-tailed, $\mathrm{P}=0.58$ \\
\hline Formal education & $55 \%$ & $48 \%$ & Fisher's exact test, two-tailed, $\mathrm{P}=0.49$ \\
\hline Religion & $\begin{array}{l}\text { 33\% Buddhist, 53\% Hindu, } \\
14 \% \text { Christian }\end{array}$ & $\begin{array}{l}\text { 44\% Buddhist, } 54 \% \text { Hindu, } 2 \% \\
\text { Christian }\end{array}$ & $\begin{array}{l}\text { Fisher's exact test, two-tailed, } \mathrm{P}=0.47 \text { (Christians } \\
\text { excluded because of small sample sizes) }\end{array}$ \\
\hline Family size & Median $=5$ & Median $=5$ & Kruskal-Wallis test, $\chi^{2}=1.69, \mathrm{P}=0.20$ \\
\hline Overall income & $77 \%$ sufficient for livelihoods & $83 \%$ sufficient for livelihoods & Fisher's exact test, two-tailed, $\mathrm{P}=0.52$ \\
\hline $\begin{array}{l}\text { Income from } \\
\text { agriculture }\end{array}$ & $33 \%$ sufficient for livelihoods & $59 \%$ sufficient for livelihoods & Fisher's exact test, two-tailed, $P=0.003$ \\
\hline $\begin{array}{l}\text { Livestock } \\
\text { ownership }\end{array}$ & $94 \%$ & $99 \%$ & Fisher's exact test, two-tailed, $\mathrm{P}=0.41$ \\
\hline No. of livestock & Median $=10$ & Median $=11$ & Kruskal-Wallis test, $\chi^{2}=0.40, \mathrm{P}=0.53$ \\
\hline Livestock grazing ${ }^{2}$ & $100 \%$ in red panda habitat & $79 \%$ in red panda habitat & \\
\hline Livestock diseases $^{2}$ & $69 \%$ noticed diseases & $91 \%$ noticed diseases & Fisher's exact test, two-tailed, $P=0.003$ \\
\hline $\begin{array}{l}\text { Veterinary } \\
\text { services }^{3}\end{array}$ & $32 \%$ sought services & $38 \%$ sought services & Fisher's exact test, two-tailed, $\mathrm{P}=0.54$ \\
\hline
\end{tabular}

${ }^{1}$ Significant differences between protected and non-protected areas are in bold.

${ }^{2}$ Includes only respondents who owned livestock ( 83 and 53 for protected and non-protected areas, respectively).

${ }^{3}$ Includes only respondents who reported livestock diseases during interviews (57 and 48 for protected and non-protected areas, respectively).

livestock owned, livestock diseases, veterinary services, and livestock grazing locations (which were verified by HPS as being either inside or outside red panda habitat). We also collected data on conservation attitudes, personal experiences, knowledge and opinions regarding red pandas. We used Fisher's exact test and a Kruskal-Wallis test to examine any differences between people living in or near protected and non-protected areas, for binary and numeric responses respectively. We then combined data from protected and non-protected areas to test the associations between conservation attitudes and 10 individual-level factors in a logistic regression. We performed all analyses

TABLE 2 Logistic regression model of individual-level factors on conservation attitudes among interview respondents $(n=142)$ from three protected and three non-protected areas in Nepal (Fig. 1).

\begin{tabular}{lrlrl}
\hline Effect & Estimate & SE & \multicolumn{1}{l}{$z$} & \multicolumn{1}{l}{$\mathrm{P}^{*}$} \\
\hline Intercept & -0.21 & 1.79 & -0.12 & 0.91 \\
Gender & 1.55 & 0.98 & 1.59 & 0.11 \\
Age & 0.04 & 0.04 & 1.01 & 0.31 \\
Education & -0.75 & 0.79 & -0.95 & 0.34 \\
Family size & -0.14 & 0.21 & -0.66 & 0.51 \\
No. of livestock & 0.05 & 0.05 & 0.89 & 0.37 \\
Overall income sufficiency & -0.17 & 0.79 & -0.22 & 0.83 \\
Agricultural income sufficiency & 0.29 & 0.85 & 0.34 & 0.73 \\
Red panda sighting & 1.03 & 1.19 & 0.87 & 0.38 \\
Awareness of conservation status & -0.05 & 1.30 & -0.04 & 0.97 \\
Awareness of legal protection & 2.03 & 0.87 & 2.34 & $\mathbf{0 . 0 2}$ \\
\hline
\end{tabular}

*The significant effect is in bold. in $R$ 3.4.1 ( $\mathrm{R}$ Development Core Team, 2012) using $\mathrm{P}=0.05$ as the significance level.

\section{Results}

The respondents from protected and non-protected areas had similar demographic and socio-economic backgrounds (Table 1), with two exceptions. Firstly, a higher percentage of the respondents from non-protected areas had sufficient income from crops alone to support their livelihoods (Table 1), which suggests that people living in or near protected areas may rely more on extracting natural resources from nearby forests. Although cultivation of crops is permitted in two of the three protected area sites (Langtang National Park and Dhorpatan Hunting Reserve), crop production is low because of harsh weather and extensive damage to crops by wild boar Sus scrofa (HPS, pers. obs.). Secondly, a higher percentage of the respondents from non-protected areas reported livestock diseases (Table 1). As the majority of respondents from both protected and non-protected areas owned livestock, allowed their livestock to graze in red panda habitat, and did not seek veterinary services for diseased livestock (Table 1), the higher incidence of livestock disease reported in nonprotected areas suggests a higher disease risk in nonprotected areas and/or a higher level of knowledge and concern for livestock health among people living in those areas.

Ninety percent of all respondents had positive attitudes towards red panda conservation, which supports our first 

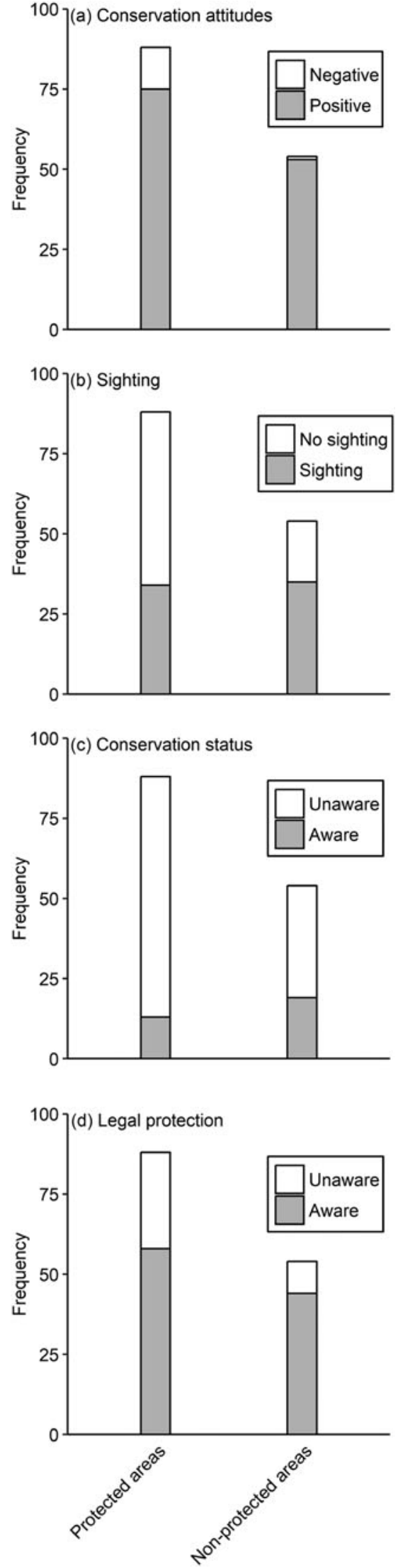

FIG. 2 Frequency of responses among interview respondents from three protected areas $(n=88)$ and three non-protected hypothesis and the findings of previous studies in Nepal (e.g. Shrestha \& Alavalapati, 2006; Baral \& Heinen, 2007; Bhattarai \& Fischer, 2014). However, people living in nonprotected areas had more positive attitudes than those living in or near protected areas (Fig. 2a), contradicting our second hypothesis. Although red pandas occur in all six sites (34 and 35 respondents from protected and non-protected areas, respectively, had seen red pandas), proportionally more respondents from non-protected than protected areas had seen them (Fig. 2b) and were more knowledgeable about the conservation status of the red panda (Fig. 2c). The respondents from non-protected areas were marginally more aware of the legal protection of red pandas than those from protected areas (Fig. 2d). People living in or near protected areas gained this knowledge of the red panda's legal status primarily from government officials and family members, whereas those living in non-protected areas gained knowledge from NGOs, media and family members (Fig. 3a). Of the individual-level factors, only awareness of the legal protection of red pandas was associated with conservation attitudes (Table 2). Ninety-seven percent of the respondents who knew about the legal protection had positive attitudes, compared to $73 \%$ of those who did not know about the legal protection.

\section{Discussion}

The lower level of dependency on natural resources, as well as more experience with and knowledge of red pandas, might have contributed to the more positive attitudes towards red panda conservation among people living in nonprotected areas. The Red Panda Network, which has been working in eastern Nepal since 2007, could also have played a role in fostering the more positive attitudes in nonprotected areas (two of our three non-protected area sites are in eastern Nepal). Nevertheless, two red pandas were found dead from unknown causes in the community forest of Ilam on 27 November 2015 (Bhattarai, 2015), where the Red Panda Network is working, suggesting there may still be a disconnect between conservation attitudes and behaviours (Waylen et al., 2009).

We suggest that awareness programmes designed specifically for school children and community groups could be effective tools for improving conservation attitudes towards red pandas in Nepal. One of the limitations of this study is

areas $(\mathrm{n}=54)$ in Nepal (Fig. 1) regarding (a) attitudes towards conservation of the red panda (Fisher's exact test, two-tailed, $\mathrm{P}=0.02$ ), (b) personal experiences of red panda sightings (Fisher's exact test, two-tailed, $\mathrm{P}=0.003$ ), (c) knowledge of the conservation status of the species (Fisher's exact test, two-tailed, $\mathrm{P}=0.007$ ), and ( $\mathrm{d}$ ) awareness of the legal protection of the species (Fisher's exact test, two-tailed, $\mathrm{P}=0.06$ ). 

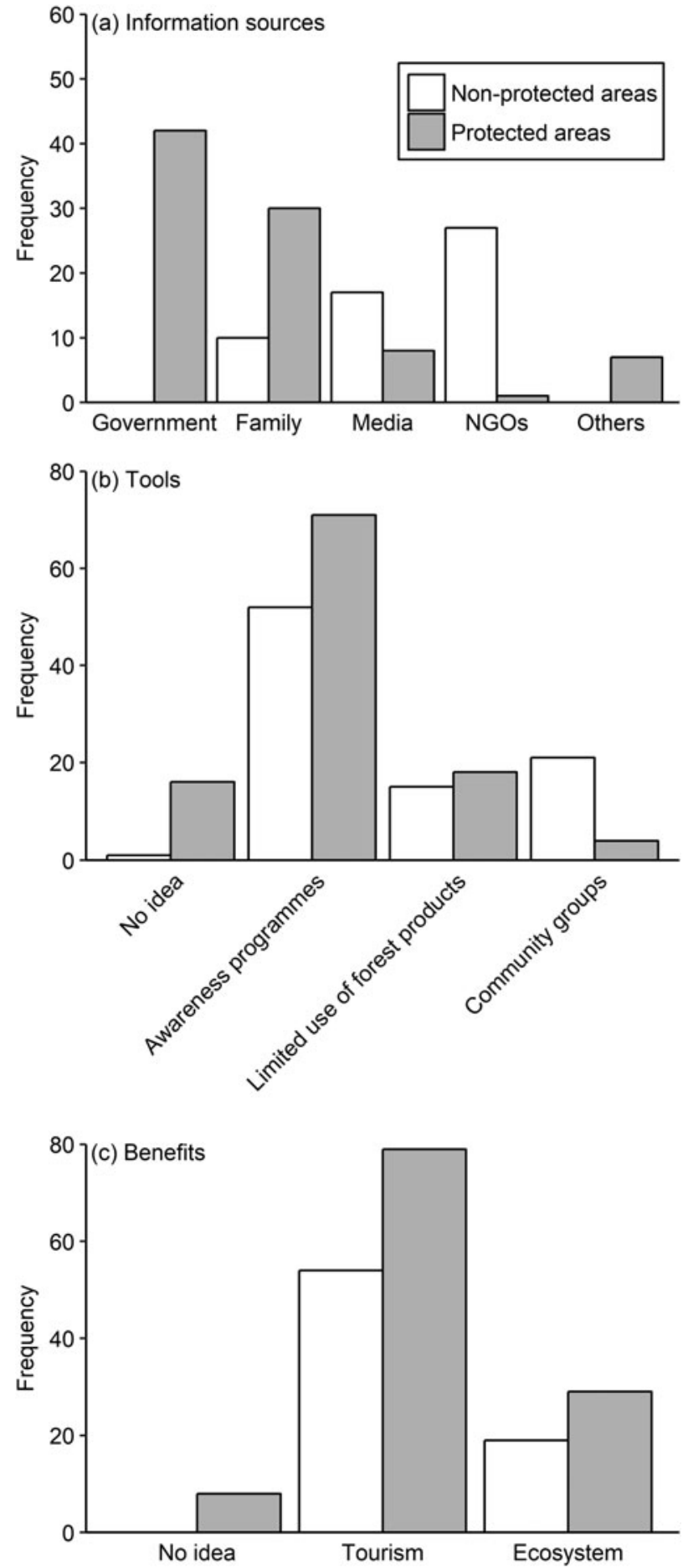

FIG. 3 Frequency of responses among interview respondents from three protected areas $(n=88)$ and three non-protected areas $(n=54)$ in Nepal (Fig. 1) regarding (a) primary sources of information about the legal protection of the species, (b) tools to improve the protection of red pandas, and (c) benefits of red panda presence. For (b) and (c), multiple answers were allowed.

that we focused only on adults, and therefore we do not have information on the conservation attitudes of the younger generation. Our data suggest that family members (often parents or other elderly relatives) are a primary source of information regarding red pandas (Fig. 3a), indicating that the older generation may have some influence on young people's attitudes towards red pandas. However, the two children with whom we spoke could not recognize red pandas in the photographs shown, and we recommend the inclusion of wildlife conservation materials in the curriculum for grade 5 students (9-10 years old). Such materials are currently included in the grade 10 curriculum (for students 1516 years old), but children in rural Nepal often leave school before they reach this grade. For community groups we recommend the government establishes regular dialogue among wildlife managers, community leaders and local people about the ecology (e.g. the impacts of livestock grazing and livestock diseases) and conservation status of red pandas. Considering that more than half of all respondents chose 'establishing awareness programmes' as a tool to protect red pandas (Fig. 3b), such efforts are likely to be welcomed by local people.

Only a small percentage of respondents chose 'limiting resource collection/grazing' as a tool to protect red pandas, and people did recognize that red pandas could bring benefits through tourism (Fig. 3c). Natural resource management plans that promote new farming practices (e.g. stall-feeding of livestock) as well as ecotourism could help red panda conservation through enhancing the livelihoods of local people (Scherl et al., 2004; Naughton-Treves et al., 2005). Alternative farming practices, such as stallfeeding, could reduce competition between livestock and red pandas (Sharma \& Belant, 2010; Dorji et al., 2012; Sharma et al., 2014) and disease risks from livestock or guard dogs (e.g. canine distemper; Bush et al., 1976; Deem et al., 2000; Loeffler et al., 2007). Although such farming practices also reduce the opportunities for local people to encounter red pandas and to develop their personal experiences with the species, ecotourism programmes could compensate for this. We recommend promoting ecotourism activities such as wildlife observation, and training local people as tour guides or hotel hosts. A combination of alternative farming practices and ecotourism may be the best approach to improve red panda conservation in Nepal.

\section{Acknowledgements}

We thank the Rufford Small Grants Foundation (Grant no. 18218-B) for funding, and the Department of National Parks and Wildlife Conservation, Department of Forests, and Ministry of Forests and Soil Conservation of the Government of Nepal for permitting this research. We thank Ashok Bahadur Bam, Bishnu Bajhagain, Bishnu Achhami, Gyazo Lama and Khum Magar for their assistance in data collection, and the local people at our study sites for their cooperation. 


\section{Author contributions}

HPS and PLS designed the study and analysed the data, HPS performed the data collection and all authors wrote the article.

\section{References}

Acharya, K.P., Paudel, P.K., Neupane, P.R. \& Köhl, M. (2016) Human-wildlife conflicts in Nepal: patterns of human fatalities and injuries caused by large mammals. PLoS ONE, 11(9), e0161717.

Baral, N. \& Heinen, J.T. (2007) Resources use, conservation attitudes, management intervention and park-people relations in the Western Terai landscape of Nepal. Environmental Conservation, $34,64-72$.

Bhattarai, B. (2015) Http://kantipur.ekantipur.com/news/2015-11-27/ 20151127095555.html. Kantipur Daily. [In Nepali]

Bhattarai, B.R. \& Fischer, K. (2014) Human-tiger Panthera tigris conflict and its perception in Bardia National Park, Nepal. Oryx, 48, 522-528.

BUDHATHOKI, P. (2004) Linking communities with conservation in developing countries: buffer zone management initiatives in Nepal. Oryx, 38, 334-341.

Bush, R.M., Montali, R.J., Brownstein, D., James, Jr, A.E. \& Appel, M.J. (1976) Vaccine induced canine distemper in a lesser panda. Journal of the American Veterinary Medical Association, 169, 959-960.

CbS (Central Bureau of Statistics) (2011) Nepal Living Standards Survey 2010/11. Statistical Report. Central Bureau of Statistics, Kathmandu, Nepal. Http://siteresources.worldbank.org/ INTLSMS/Resources/3358986-1181743055198/38773191329489437402/Statistical_Report_Vol1.pdf [accessed 26 July 2017].

Deem, S.L., Spelman, L.H., Yates, R.A. \& Montali, R.J. (2000) Canine distemper in terrestrial carnivores: a review. Journal of Zoo and Wildlife Medicine, 31, 441-451.

Dewu, S. \& Røskaft, E. (2017) Community attitudes towards protected areas: insights from Ghana. Oryx, https://doi.org/10.1017/ Soo30605316001101.

Dorji, S., Rajaratnam, R. \& Vernes, K. (2012) The Vulnerable red panda Ailurus fulgens in Bhutan: distribution, conservation status and management recommendations. Oryx, 46, 536-543.

Gebresenbet, F., Baraki, B., Yirga, G., Sillero-Zubiri, C. \& BAUER, H. (2017) A culture of tolerance: coexisting with large carnivores in the Kafa Highlands, Ethiopia. Oryx, https://doi.org/10. 1017/Soo30605316001356.

Glatston, A., Wei, F., Zaw, T., \& Sherpa, A. (2015) Ailurus fulgens. In The IUCN Red List of Threatened Species 2015. Http://dx.doi.org/ 10.2305/IUCN.UK.2015-4.RLTS.T714A45195924.en [accessed 26 July 2017].

Glatston, A.R. \& Gebauer, A. (2011) People and red pandas: the red panda's role in economy and culture. In Red Panda: Biology and Conservation of the First Panda (ed. A.R. Glatston), pp. 11-25. Academic Press, London, UK.

HMG (His Majesty's Government) (1979) The Himalayan National Parks Regulation. Ministry of Law and Justice, Kathmandu, Nepal.

IUCN (2017) Protected Areas Categories. Https://www.iucn.org/ theme/protected-areas/about/protected-areas-categories [accessed 26 July 2017].
Kandel, K., Huettmann, F., Suwal, M.K., Regmi, G.R., Nijman, V., Nekaris, K.A.I. et al. (2015) Rapid multi-nation distribution assessment of a charismatic conservation species using open access ensemble model GIS predictions: red panda (Ailurus fulgens) in the Hindu-Kush Himalaya region. Biological Conservation, 181, 150-161.

Loeffler, I.K., Howard, J., Montali, R.J., Hayek, L.A., Dubovi, E., ZHANG, Z. et al. (2007) Serosurvey of ex situ giant pandas (Ailuropoda melanoleuca) and red pandas (Ailurus fulgens) in China with implications for species conservation. Journal of Zoo and Wildlife Medicine, 38, 559-566.

Mir, Z.R., Noor, A., Habib, B. \& Veeraswami, G.G. (2015) Attitudes of local people toward wildlife conservation: a case study from the Kashmir valley. Mountain Research and Development, 35, 392-400.

Mishra, C., Allen, P., McCarthy, T., Madhusudan, M.D., Bayarjargal, A. \& Prins, H.H.T. (2003) The role of incentive programs in conserving the snow leopard. Conservation Biology, 17, 1512-1520.

Naughton-Treves, L., Holland, M.B. \& Brandon, K. (2005) The role of protected areas in conserving biodiversity and sustaining local livelihoods. Annual Review of Environment and Resources, 30, 219-252.

R Development Core Team (2012) R: A Language and Environment for Statistical Computing. R Foundation for Statistical Computing, Vienna, Austria. Http://www.R-project.org

Scherl, L.M., Wilson, A., Wild, R., Blockhus, J.M., Franks, P., McNeely, J.A. \& McShane, T. (2004) Can Protected Areas Contribute to Poverty Reduction? Opportunities and Limitations. IUCN, Gland, Switzerland, and Cambridge, UK.

Sharma, H.P. \& Belant, J.L. (2010) Threats and conservation of red pandas in Dhorpatan Hunting Reserve, Nepal. Human Dimensions of Wildlife, 15, 299-300.

Sharma, H.P., Belant, J.L. \& Swenson, J.E. (2014) Effects of livestock on occurrence of the Vulnerable red panda Ailurus fulgens in Rara National Park, Nepal. Oryx, 48, 228-231.

Shrestha, R.K. \& Alavalapati, J.R.R. (2006) Linking conservation and development: an analysis of local people's attitude towards Koshi Tappu Wildlife Reserve, Nepal. Environment, Development and Sustainability, 8, 69-84.

Talukdar, S. \& Gupta, A. (2017) Attitudes towards forest and wildlife, and conservation-oriented traditions, around Chakrashila Wildlife Sanctuary, Assam, India. Oryx, https://doi.org/10.1017/ So030605316001307.

Waylen, K.A., McGowan, P.J.K., Pawi Study Group \& Milner-Gulland, E.J. (2009) Ecotourism positively affects awareness and attitudes but not conservation behaviours: a case study at Grande Riviere, Trinidad. Oryx, 43, 343-351.

Williams, B.H. (2004) The status of the red panda in Jamuna and Mabu villages of eastern Nepal. MA thesis. San José State University, California, USA.

\section{Biographical sketches}

Hari Sharma studies the conservation of red pandas in Nepal and is interested in wildlife ecology. JE R RO LD BELANT studies carnivore ecology, human-wildlife interactions, and international conservation. PEI-Jen SHaner studies mammal ecology and wildlife diseases. 